\title{
Energia da biomassa de cana-de-açúcar sob influência de hidrogel, cobertura vegetal e profundidade de plantio
}

Tadeu A. Marques ${ }^{1} \&$ Luis E. V. Pinto ${ }^{1}$

\section{RESUMO}

A colheita mecanizada é melhor executada em sulcos rasos. O palhiço promove maior retenção hídrica, diminui a evaporação superficial mas compromete a brotação. Polímeros alteram a fisiologia disponibilizando água e nutrientes. O objetivo deste trabalho foi compreender a relação da forma de plantio, do uso de palhiço em cobertura e do uso de polímeros condicionadores, com a produção de bioenergia (do colmo, do palhiço e do sistema), com a produtividade (de colmo, do palhiço e de biomassa), com a fibra e com o açúcar total (ATR). Utilizou-se a soqueira de cana-de-açúcar em parcelas subdividas $(2 \times 4)$, ou seja, duas profundidades e quatro doses do polímero. As parcelas foram subdivididas em tratamentos com quatro quantidades de matéria seca com três repetições. $\mathrm{O}$ uso de cobertura na quantidade de $5 \mathrm{t} \mathrm{ha}^{-1}$ foi prejudicial para a produtividade de cana-de-açúcar, biomassa e bioenergia. A forma de plantio e a utilização de polímero não alteraram as variáveis estudadas. Existe relação linear entre produtividade e bioenergia do colmo, produtividade de palhiço e bioenergia do palhiço. A bioenergia do sistema apresenta relação linear com a biomassa, fibra e ATR. A bioenergia se divide em $82,6 \%$ no colmo e $17,4 \%$ no palhiço.

Palavras-chave: Saccharum, bioenergia, poder calorífico

\section{Biomass energy from sugarcane under influence of hydrogel, vegetation cover and planting depth}

\begin{abstract}
The mechanized harvesting is best performed in shallow furrows. The straw promotes greater retention of water, reduces evaporation from the surface, but affects the budding. The polymers modify the physiology providing water and nutrients. The objective of this study was to understand the relationship of form of planting, straw and polymers with bioenergy (of the stalk, straw and system), productivity (stalks, straw and biomass), fiber and total recoverable sugar (TRS). The sugarcane ratoon has been used in plots $(2 \mathrm{x}$ 4), that is, two depths and four doses of the polymer. The plots were subdivided into treatments with four doses of dry matter and three repetitions. The use of dose of $5 \mathrm{tha}^{-1}$ as top dressing was detrimental to the productivity of sugarcane, biomass and bioenergy. The form of planting and the use of polymer did not affect the studied variables. There is a linear relationship between productivity and bioenergy stalk, straw and bioenergy productivity of trash. The bioenergy system has a linear relationship with biomass, fiber and TRS. The bioenergy is divided into $82.6 \%$ in stalk and $17.4 \%$ in straw.
\end{abstract}

Key words: Saccharum, bionergy, calorific power 


\section{INTRODUÇÃO}

A cogeração em usinas sucroalcooleiras apresentou, nos últimos anos, expansão na matriz energética brasileira sinalizando um avanço no aproveitamento da energia contida na biomassa vegetal (bioenergia) sendo este aproveitamento bioenergético discutido pela academia científica internacional, para diferentes fontes vegetais. Alguns pesquisadores acreditam que até a próxima ela será denominada "Era da bioenergia" (Mintom, 2009) oriunda principalmente de material vegetal transformado por micro-organismos (Steiner et al., 2011). O aproveitamento da energia da biomassa desponta ecológica, financeira e tecnologicamente adequado. A expansão da cogeração ocorre em um período de crescente demanda energética e de grandes números de pesquisas internacionais sobre as energias renováveis produzidas com sustentabilidade (Santos et al., 2011).

No caso brasileiro da bioenergia com a cultura da cana-deaçúcar, o panorama envolve a necessidade de alterações nos fatores de produção visando a aumentos nas produtividades, viabilização com problemas ambientais e ecológicos tal como superação de problemas relativos às novas áreas de cultivo, oeste paulista, centro-oeste brasileiro e norte do Paraná. Em sulco profundo o plantio de cana-de-açúcar é o modelo tradicionalmente usado para a cultura canavieira brasileira. A sulcação é realizada na profundidade entre 0,25 a $0,40 \mathrm{~m}$ em relação ao nível do solo, o espaçamento utilizado varia de 1,40 a 1,50 $\mathrm{m}$ haja vista que os maquinários utilizados para esta operação não possuem mais do que $2,0 \mathrm{~m}$ de bitola (Roque et al., 2010). O plantio em leira ou canteirização, é uma técnica alternativa, através da qual todo trânsito na lavoura é feito com os rodados entre as fileiras de cana-de-açúcar, em que o principal objetivo é viabilizar o plantio mecanizado e a colheita mecanizada em cana-de-açúcar de primeiro corte, além de reduzir a compactação do solo e evitar baixas produtividades para a cultura canavieira (Rosas, 2007). Segundo Carr et al. (2008) a canteirização do canavial é uma técnica eficaz para a produção da cultura de cana-de-açúcar, passível de ainda ser ainda ser potencializada quando a cana for plantada em linha dupla, com espaçamento mais largo que $1,8 \mathrm{~m}$.

Com relação à necessidade de água da cana-de-açúcar, temse que a região centro-sul produz a cana-de-açúcar em sequeiro e frequentemente utilizam da irrigação denominada "salvação", sobretudo nas épocas de plantio e de crescimento vegetativo. Quando o plantio executado é para cana de ano (outubro, novembro e dezembro) existe a possibilidade de se utilizar a vinhaça, resíduo líquido da fabricação do bioetanol; no entanto, quando a cana-de-açúcar é plantada como cana de ano e meio (janeiro, fevereiro e março) e ocorrem veranicos, a utilização de água em irrigação é vital. Nas áreas de expansão da cultura canavieira esses veranicos são mais frequentes, demandando técnicas que possam minimizar o problema visto que plantio em canteiro, ou raso, apresentará maior estresse hídrico à planta em razão do sistema radicular superficial. Com atenção especial nas questões ambientais de sustentabilidade e legais, sobre a outorga e o uso da água, deve-se ater que as regiões de expansão apresentam índice pluviométrico anual adequado; contudo, a distribuição das chuvas é irregular sendo que, em solos arenosos e com baixa capacidade de retenção, agronomicamente esta água da chuva é perdida devendo-se, portanto, pensar em alternativas para seu uso agronômico. Existem polímeros sintéticos recomendados para uso agrícola como condicionadores de solo. As dosagens dependem dos fatores solo, cultura, clima, tipo de planta, quantidade de água, sistema de aplicação e diagnóstico do local de aplicação. Os polímeros possuem capacidade de retenção da água do solo com tensão maior que as partículas naturais do solo; apesar disto, esta tensão é menor que a tensão de sucção pelas raízes das plantas. Este fato possibilita maior retenção de água e nutrientes no solo, por serem prontamente liberados para as plantas (Azevedo et al., 2002). Albuquerque Filho et al. (2009) relatam que algumas características do solo, como porosidade, capacidade de armazenamento e evaporação, podem ser alteradas e promover mudanças nos fatores de produção, como frequência de irrigação e doses de nutrientes recomendados. A utilização de cobertura vegetal também é uma técnica utilizada para diminuir a evaporação de água do solo e incrementar o teor de matéria orgânica no solo, promovendo maiores valores de retenção de água. O palhiço é o material remanescente ao solo após a colheita mecanizada da cana-de-açúcar, sendo constituído de folhas verdes, folhas secas, ponteiros, frações de colmo de pequenas dimensões e, eventualmente, de raízes e partículas de terra a eles aderidas (Ripoli \& Ripoli, 2004). O palhiço pode ser recolhido e enviado às unidades industriais visando à geração de energia elétrica ou pode ser deixado no campo como matéria orgânica (Michelazzo \& Braunbeck, 2008). A deposição e a manutenção do palhiço sobre a superfície do solo apresentam aspectos positivos e negativos para a cultura canavieira (Souza et al., 2005).

Alterações estão ocorrendo no sistema de produção da cana-de-açúcar e novas propostas vêm sendo investigadas cientificamente com relação à viabilidade de uso. Neste contexto se observam a colheita mecanizada, canteirização, o manejo do palhiço após a colheita e utilização de novas substâncias aditivas ao solo, com a finalidade de correções. Fatores utilizados no sistema de produção promovem mudanças quantitativas e qualitativas na cana-de-açúcar produzida. As interações entre os fatores podem promover sinergia e mudanças ainda maiores.

A colheita mecanizada é melhor executada quando o plantio se dá em sulcos rasos ou até mesmo em canteirização. Esta técnica pode comprometer a produtividade e a qualidade da cana-de-açúcar devido ao sistema radicular superficial mais susceptível ao estresse hídrico. Palhiço em cobertura promove maior retenção hídrica diminuindo a evaporação superficial do solo, mas compromete a brotação da soqueira e pode ser utilizado por pragas, alterando a produtividade e a qualidade da cana-de-açúcar. A utilização de substâncias hidrorretentoras disponibiliza água e nutrientes para as raízes podendo alterar a fisiologia da cana-de-açúcar; contudo, elevam o custo de produção. Como hipótese, supõe-se haver uma combinação entre esses fatores citados que permita maior produtividade e melhor qualidade da cana-de-açúcar potencializando a produção de bioenergia do sistema.

O objetivo deste trabalho foi compreender a relação entre profundidade de plantio, manejo do palhiço em cobertura e utilização de polímeros condicionadores de solo com a bioenergia do colmo (BC), bioenergia do palhiço (BP), bioenergia total do sistema (BS) produtividade, fibra e ATR. 


\section{Material e MÉtodos}

O experimento foi realizado no campo experimental da Universidade do Oeste Paulista, município de Presidente Prudente, SP, nas coordenadas geográficas $22^{\circ} 07^{\prime} 04^{\prime \prime} \mathrm{S}, 51^{\circ}$ 22' 04" W e altitude de $430 \mathrm{~m}$. De acordo com a classificação de Koppen, a região apresenta clima Aw.

O solo foi caracterizado como Argissolo Vermelho-Amarelo Distroférrico, típico A moderado, textura médio-argilosa, segundo classificação da Empresa Brasileira de Pesquisa Agropecuária (EMBRAPA). Foi realizada uma amostragem composta de solo no local do experimento e determinadas às correções e adubações, segundo Espironelo (1992). Não foi necessária a adição de calcário para correção da acidez mas sim a adubação com o equivalente a 0,135 e $135 \mathrm{~kg} \mathrm{ha}^{-1}$ de N, P2O5 e K2O, respectivamente, utilizando-se $675 \mathrm{~kg} \mathrm{ha}^{-1}$ do formulado 00-20-20, no plantio. As plantas receberam, ainda, 30,8 $\mathrm{kg} \mathrm{ha}^{-1}$ de $\mathrm{N}$, na forma de $70 \mathrm{~kg} \mathrm{ha}^{-1}$ de ureia $(44 \% \mathrm{~N})$ como adubação em cobertura, quando estavam com altura média de $0,20 \mathrm{~m}$.

$\mathrm{O}$ polímero utilizado no ensaio é uma mistura de dois produtos, Hydroplan-EB/HyB-M e Hydroplan-EB/HyC. Segundo o fabricante, seus constituintes são uma mistura de Copolímero de Acrilamida e Acrilato de Potássio, empregados para absorver e reter grandes quantidades de água e nutrientes. O tamanho das partículas varia de 0,3 a $1 \mathrm{~mm}$ e sua absorção de água no solo (medida sob pressão de $305,7 \mathrm{kPa}$ ) varia de $100 \mathrm{a}$ 250 gramas de água por grama do produto, com pH utilizável do produto ao solo, entre 5,0 e 9,0. O polímero foi aplicado no fundo do sulco da cana, seco e antes da deposição dos colmos para o plantio.

Utilizou-se a soqueira da cultivar RB 867515 , após colheita realizada em junho de 2009. O esquema experimental foi o de blocos com parcelas subdivididas ( $2 \times 4)$, duas formas de plantio (blocos 1 e 2) (sulco $+0,30 \mathrm{~m}$ ) e (leira $-0,30 \mathrm{~m}$ ) cada bloco foi composto de quatro doses do polímero $(0 ; 26,67 ; 53,33 \mathrm{e}$ $80,00 \mathrm{~kg} \mathrm{ha}^{-1}$ ) pois, segundo informações do fabricante, a dose recomendada é $40 \mathrm{~kg} \mathrm{ha}^{-1}$. As parcelas foram subdivididas em quatro tratamentos $\left(0,5,10\right.$ e $\left.15 \mathrm{tha}^{-1}\right)$ de matéria seca (MS) oriunda do palhiço produzido na colheita. Três amostragens foram realizadas para cada para cada variável analisada (três repetições). A subparcela foi composta de cinco linhas com cinco metros de comprimento, com o espaçamento entre linhas de $1,5 \mathrm{~m}$ (área de $37,5 \mathrm{~m}^{2}$ ).

Após 14 meses de crescimento vegetativo (agosto de 2010) realizaram-se as análises para determinação dos parâmetros tecnológicos (Fibra e ATR) segundo metodologia descrita por Fernandes (2011) e poder calorífico superior utilizandose bomba calorimétrica Cal2k, de acordo com a Associação Brasileira de Normas Técnicas (ABNT).

Realizaram-se, após as amostragens e determinações analíticas (agosto de 2010) a colheita do experimento, a separação de colmo e palhiço (folhas + ponteiros) e suas respectivas pesagens para a determinação das produtividades de biomassa total, colmo e palhiço produzidos de acordo com Segato et al. (2006). Utilizaram-se das Eqs. 1, 2 e 3 para determinar a bioenergia total em terajoule por hectare $\left(\mathrm{TJ} \mathrm{ha}^{-1}\right)$, captado do sol pela cana-de-açúcar e convertido em biomassa por hectare, determinando-se o poder calorífico através da utilização de bomba calorimétrica Cal2k, do colmo, do palhiço e se calculando por soma, o poder calorífico total.

$$
\begin{aligned}
& \mathrm{BC}=\frac{\mathrm{PC} \times \mathrm{PROD} c}{1000} \\
& \mathrm{BP}=\frac{\mathrm{PC} p \times \text { PRODp }}{1000} \\
& \mathrm{BS}=\frac{\mathrm{PCb} \times \mathrm{PRODb}}{1000}
\end{aligned}
$$

sendo:

$\mathrm{BC}$ - bioenergia do colmo, $\mathrm{TJ}_{\mathrm{ha}} \mathrm{H}^{-1}$

PCc - poder calorífico do colmo, $\mathrm{MJ} \mathrm{ha}^{-1}$

PRODc - produtividade agrícola de colmo, $\mathrm{t} \mathrm{ha}^{-1}$

BP - bioenergia do palhiço, $\mathrm{TJ}_{\mathrm{ha}}{ }^{-1}$

PCp - poder calorífico do palhiço, $\mathrm{MJ} \mathrm{ha}^{-1}$

PRODp - produtividade agrícola do palhiço, $\mathrm{t} \mathrm{ha}^{-1}$

BS - bioenergia total do sistema, $\mathrm{TJ} \mathrm{ha}^{-1}$

$\mathrm{PCb}$ - poder calorífico da biomassa, $\mathrm{MJ} \mathrm{ha}^{-1}$

$\mathrm{PRODb}$ - produtividade agrícola da biomassa, $\mathrm{t} \mathrm{ha}^{-1}$

Todos os dados foram submetidos à análise de variância (ANOVA) e ao teste de comparação de médias Scott-Knott ( $\mathrm{p}$ $<0,05$ ) segundo Banzatto \& Kronka (2006). Para a confecção dos gráficos e regressões estatísticas utilizou-se o programa matemático Microcal Origin 6.0, e se realizou o teste F para a regressão calculando-se, enfim, o coeficiente de determinação (COD) também conhecido como $\mathrm{R}^{2}$.

\section{Resultados E Discussão}

Observa-se, na Tabela 1, que apenas o fator de variação $\mathrm{C}$ (cobertura) apresentou teste $\mathrm{F}$ com significância para as variáveis Biomassa, $\mathrm{TCH}, \mathrm{BC}$ e $\mathrm{BS}$ sendo que, para todas as variáveis, a utilização de $5 \mathrm{t} \mathrm{ha}^{-1}$ de palhiço promoveu diminuição de valores, como relatado por Souza et al. (2005) que o palhiço em cobertura pode apresentar interação negativa para a cultura canavieira, dificultar a brotação e proporcionar o desenvolvimento de pragas e doenças. Quantidades maiores

Tabela 1. Resumo da análise de variância (teste F) para as variáveis estudadas

\begin{tabular}{lcccc}
\hline \multirow{2}{*}{ Variáveis } & \multicolumn{4}{c}{ Fator de variação } \\
\cline { 2 - 5 } Fibra & P & D & C & PxC \\
ATR & NS & NS & NS & NS \\
Biomassa & NS & NS & NS & NS \\
TCH & NS & NS & $7,77^{* *}$ & NS \\
Palhiço & NS & NS & $8,65^{\star *}$ & NS \\
BC & NS & NS & NS & NS \\
BP & NS & NS & $8,43^{* *}$ & NS \\
BS & NS & NS & NS & NS \\
\hline P-Pla & NS & NS & $7,48^{\star *}$ & NS \\
\hline
\end{tabular}

P-Plantio; D-Dose de polímero hidrogel; C-Cobertura de palhico; $\mathrm{P} \times \mathrm{C}$, Plantio $\times$ Cobertura de palhiço, Fibra - Teor em \% da fibra industrial da cana; ATR - açúcar total recuperável, em kg t-1; Biomassa - valor total de biomassa produzida ha- ${ }^{-1}$ TCH - t ha- ${ }^{-1}$ de colmo; Palhiço - $t$ ha ${ }^{-1}$ de palhiço (folhas secas + folhas verdes + ponteiros); $B C$ - Bioenergia do colmo produzida TJ ha- ${ }^{-1}$, BP - Bioenergia do palhiço produzida TJ ha-1 ${ }^{-1}$ BS - Bioenergia total produzida $\mathrm{TJ} \mathrm{ha}^{-1}$ 
apresentaram recuperação dos valores indicando serem interessantes para o sistema de produção, pois, segundo Canellas et al. (2003) e Bezerra \& Cantalice (2009) ocorreu um aumento na produtividade de colmos quando os resíduos da cana--de-açúcar foram deixados como cobertura, gerando acréscimos de 10 t ha $^{-1}$ ano $^{-1}$ e Ceddia et al. (1999) relataram que a matéria orgânica melhora as propriedades do solo e também pode modificar a capacidade de retenção de água.

Para o polímero, os resultados indicaram que o uso de polímero hidrogel não proporcionou diferenças nas variáveis analisadas com 14 meses de crescimento, apesar de poder ter apresentado maior desenvolvimento radicular e parte aérea durante a fase de crescimento, como relatado por Martins et al. (2004), Vale et al. (2006), Demartelaere et al. (2009) e Lopes et al. (2010) e explicado por Gervázio \& Frizzone (2004) de que polímeros promoveram a melhoria física nos solos com relação à retenção de água e proporcionaram melhor ambiente para crescimento das plantas.

Outro fato interessante e muito importante a ser observado na Tabela 1 , é que o fator plantio não apresentou teste $\mathrm{F}$ significativo indicando que foi igual estatisticamente para as variáveis analisadas e que a interação entre plantio e cobertura não apresentou $\mathrm{F}$ significativo, sinal de que não há interação entre os fatores, o que pode indicar que a canteirização não promove alterações, mesmo quando utilizado palhiço em cobertura, sendo uma técnica interessante para as lavouras canavieira.

Na Figura 1 se encontra a curva de correlação entre a produtividade de colmos por hectare e a bioenergia do colmo (BC). Observa-se que a correlação foi significativa a nível de $1 \%$ e o coeficiente de determinação da equação $\left(R^{2}\right)$ foi de 0,88 . Deste resultado inferir que alterações de produtividade levarão a alterações na bioenergia do colmo.

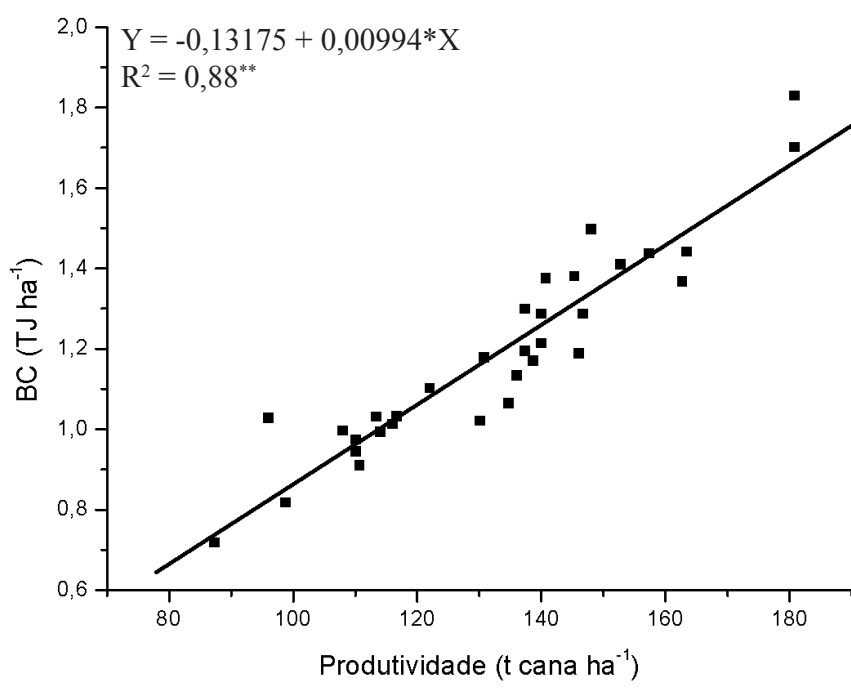

Figura 1. Correlação entre produtividade de cana-de-açúcar e bioenergia do colmo - BC (TJ ha $\left.{ }^{-1}\right)$

Para o palhiço produzido pode-se observar, na Figura 2, a curva de correlação entre a produtividade de palhiço por hectare e a bioenergia do palhiço (BP). Verificou-se uma correlação significativa a nível de $1 \%$ e o coeficiente de determinação da equação $\left(r^{2}\right)$ foi de 0,54 demonstrando que

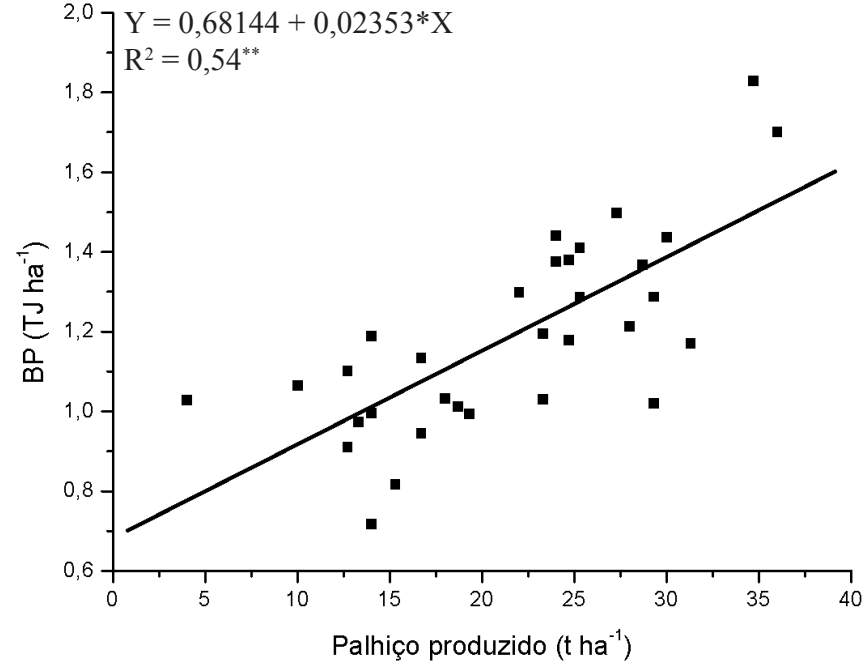

Figura 2. Correlação entre palhiço produzido (t ha-1) e bioenergia do palhiço - BP $\left(T J h^{-1}\right)$

maiores produtividades de palhiço levam a maior produção de bioenergia de palhiço.

Na Figura 3 a correlação entre a produção de biomassa por hectare e a bioenergia do sistema (BS) é significativa a nível de 0,01 e o coeficiente de determinação da equação $\left(\mathrm{R}^{2}\right)$ foi de 0,86 . Aumentos na biomassa acarretam aumentos na bioenergia do sistema (BS).

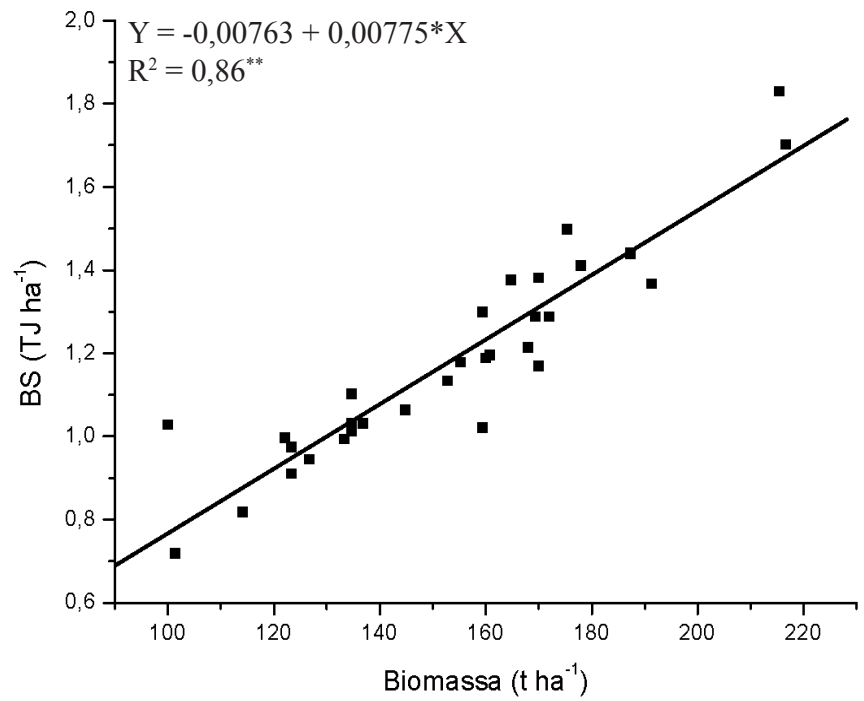

Figura 3. Correlação entre de biomassa (t ha-1) e bioenergia do sistema - BS (TJ ha-1)

Observou-se, para a fibra da cana (Figura 4) correlação entre a produção de bioenergia do sistema (BS) com a produção de fibra significativa a nível de 0,01 com coeficiente de determinação $\left(\mathrm{R}^{2}\right)$ de 0,91. Segundo Inman-Bamber et al. (2011) alguns clones de cana-de-açúcar podem produzir maiores quantidades de fibra sem reduções significativas no teor de sacarose, o que resultará, sem dúvida, em maior bioenergia do sistema, como observado nesses resultados.

Observa-se, na Figura 5, correlação entre teores de ATR produzidos por hectare e bioenergia do sistema (BS) significativa a nível de 0,01 com coeficiente de determinação da equação 


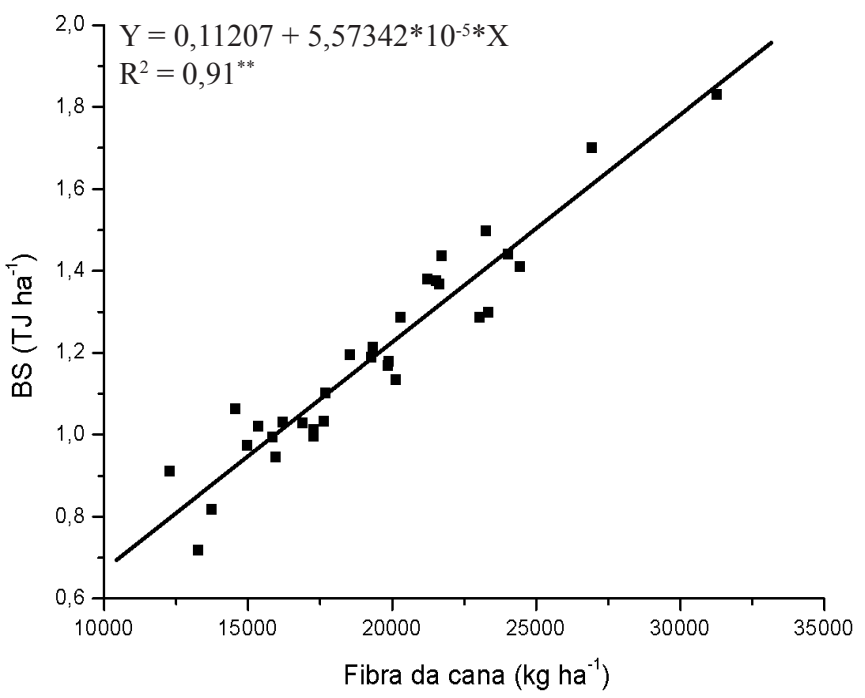

Figura 4. Correlação entre a fibra da cana $\left(\mathrm{kg} \mathrm{ha}^{-1}\right) \mathrm{e}$ a bioenergia do sistema - BS (TJ ha-1)

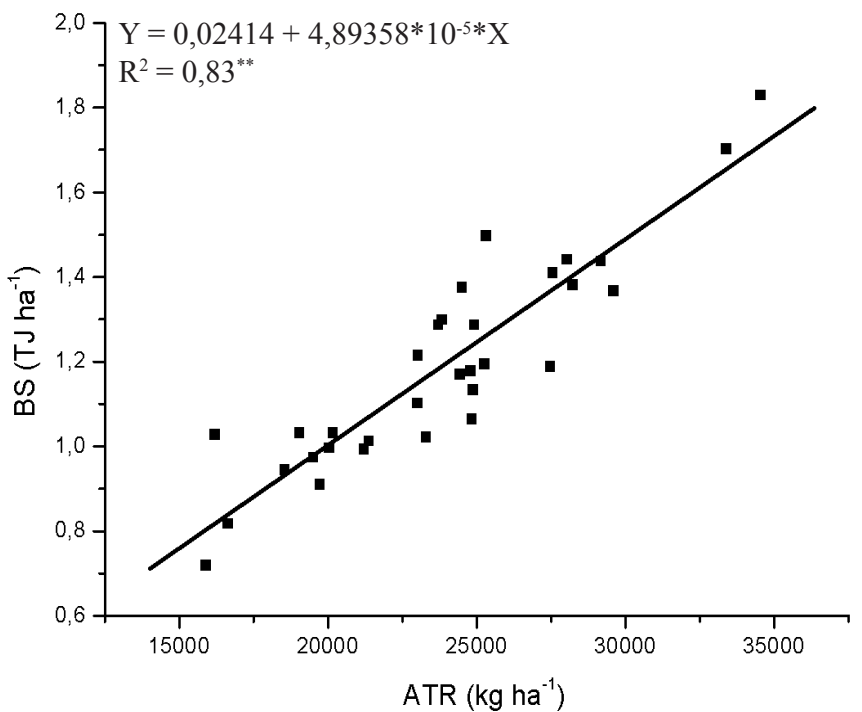

Figura 5. Correlação entre o açúcar total recuperável da cana - ATR $\left(\mathrm{kg} \mathrm{ha}^{-1}\right)$ e bioenergia do como (TJ ha $\left.{ }^{-1}\right)$

$\left(\mathrm{R}^{2}\right)$ de 0,83 . $\mathrm{O}$ açúcar possui poder calorífico equivalente a aproximadamente $16,55 \mathrm{MJ} \mathrm{kg}^{-1}$ que contribuem para o valor energético total da cana-de-açúcar, Inman-Bamber et al. (2011). O crescimento vegetativo da cana promoveu reações anabólicas e catabólicas que não alteraram as concentrações, mas promoveram elevações no valor total por área.

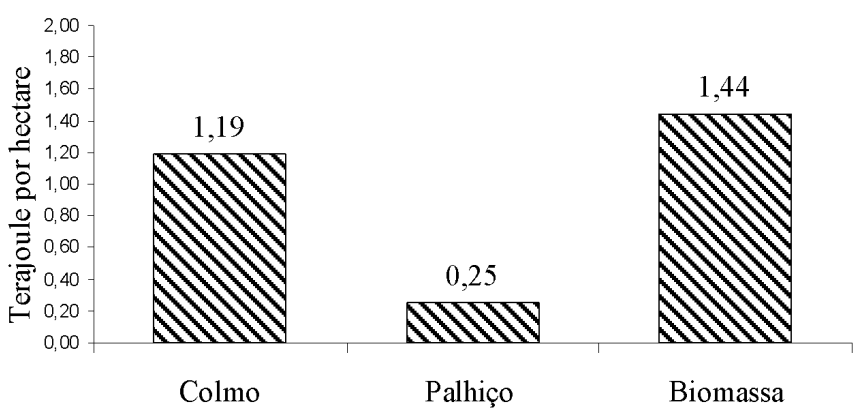

Figura 6. Relação da produção de bioenergia em TJ ha ${ }^{-1}$ por constituintes de biomassa canavieira
Observa-se, na Figura 6, que a bioenergia do sistema é formada pela bioenergia do colmo $(82,6 \%)$ e pela bioenergia do palhiço $(17,4 \%)$.

\section{Conclusões}

1. A quantidade de $5 \mathrm{t} \mathrm{ha}^{-1}$ de cobertura vegetal reduz a produção de biomassa, de colmo e de bioenergia do colmo (BC).

2. A utilização de hidrogel não apresentou efeito nas variáveis estudadas.

3. A forma de plantio, raso ou profundo, não alterou as variáveis estudadas.

4. Existe uma relação linear entre produtividade e a bioenergia do colmo, bem como produtividade de palhiço e bioenergia do palhiço.

5. A bioenergia do sistema apresenta relação linear com a biomassa, fibra e açúcar total recuperável.

6. A bioenergia do sistema se divide em $82,6 \%$ na bioenergia do colmo e $17,4 \%$ na bioenergia do palhiço.

\section{Literatura Citada}

Albuquerque Filho, J. A. C. de; Lima, V. L. A. de; Menezes, D.; Azevedo, C. A. V. de; Dantas Neto, J.; Silva Júnior, J. G. da. Características vegetativas do coentro submetido a doses do polímero hidroabsorvente e lâminas de irrigação. Revista Brasileira de Engenharia Agrícola Ambiental, v.13, p.671-679, 2009.

Azevedo, T. L. de; Bertonha, A.; Gonçalves, A. C. A. Uso de hidrogel na agricultura. Revista do Programa de Ciências Agro-Ambientais, v.1, p.23-31, 2002.

Banzatto, D. A.; Kronka, S. N. Experimentação agrícola. 4.ed. Jaboticabal: FUNEP, 2006. 237p.

Bezerra, S. A.; Cantalice, J. R. B. Influência da cobertura do solo nas perdas de água e desagregação do solo em entressulcos. Revista Caatinga, v.22, p.18-28, 2009.

Canellas, L. P.; Velosso, A. C. X.; Marciano, C. R.; Ramalho, J. F. G. P.; Rumjanek, V. M.; Rezende, C. E.; Santos, G. A. Propriedades químicas de um cambissolo cultivado com cana-de-açúcar, com preservação do palhiço e adição de vinhaça por longo tempo. Revista Brasileira de Ciências do Solo, v.27, p.935-944, 2003.

Carr, A. P.; Carr, D. R.; Carr, I. E.; Wood, A. W.; Poggio, M. Implementing sustainable farming company experience. Australian Society of Sugarcane Techonologist, v.30, p.2533, 2008.

Ceddia, M. B.; Anjos, L. H. C. dos; Lima, E.; Neto, A. R.; Silva, L. A. Sistemas de colheita da cana-de-açúcar e alterações nas propriedades físicas de um solo podzólico amarelo no estado do Espírito Santo. Pesquisa Agropecuária Brasileira, v.34, p.1467-1473, 1999.

Demartelaere, A. C. F.; Dutra, I.; Alves, S. S. V.; Teófilo, T. M. da S.; Alves, S. V. Utilização de polímero hidroabsorvente no meloeiro (Cucumis melon L.) sob diferentes lâminas de irrigação. Revista Caatinga, v.22, p.5-8, 2009. 
Espironelo, A. Cana-de-açúcar. In: Raij, B. van; Silva, N. M. da; Bataglia, O. C.; Quaggio, J. A.; Hiroce, R.; Cantarella, H.; Bellinazzi Júnior, R.; Dechen, A. R.; Trani, P. E. (ed.) Recomendações de adubação e calagem para o Estado de São Paulo. Campinas: Instituto Agronômico, 1997. p.237242. Boletim Técnico, 100

Fernandes, A. C. Cálculos na Agroindústria da cana-de-açúcar. STAB, 3.ed., 2011. 416p.

Gervázio, E. S.; Frizzone, J. A. Caracterização físico-hídrica de um condicionador de solos e seus efeitos quando misturado a um substrato orgânico. Revista Irriga, v.9, p. 95-105, 2004.

Inman-Bamber, N. G.; Jackson, P. A.; Hewit, M. Sucrose accumulation in sugarcane stalks does not limit photosynthesis and biomass production. Crop \& Pasture Science, v.62, p.848-858, 2011.

Lopes, J. L. W.; Silva, M. R. da; Saad, J. C. C.; Angélico, T. dos S. uso de hidrogel na sobrevivência de mudas de Eucalyptus urograndis produzidas com diferentes substratos e manejos hídricos. Revista Ciência Florestal, v.20, p.217-224, 2010.

Martins, C. C.; Reis, E. F. dos; Busato, C.; Pezzopane, J. E. M. Desenvolvimento inicial do cafeeiro conilon (Coffea canephora Pierre) submetido a diferentes turnos de rega e doses de hidroabsorvente. Revista Engenharia na Agricultura, v.12, 222-228, 2004.

Michelazzo, M. B.; Braunbeck, O. A. Análise de seis sistemas de recolhimento do palhiço na colheita mecânica da canade-açúcar. Revista Brasileira de Engenharia Agrícola Ambiental, v.12, p.546-552, 2008.
Mintom, P. N. The biofuel future? Chemistry World, v.6, p.4043, 2009.

Ripoli, T. C. C.; Ripoli, M. L. C. Biomassa de cana-de-açúcar: colheita, energia e ambiente. Piracicaba: Barros \& Marques Editoração Eletrônica, 2004. 302p.

Roque, A. A. de O.; Zigoman, M. de S.; Ronny, S. B.; Souza, G. $\mathrm{S}$. Controle de tráfego agrícola e atributos físicos do solo em área cultivada com cana-de-açúcar. Pesquisa Agropecuária Brasileira, v.45, p.744-750, 2010.

Rosas, J. Características de novas versões de plantadoras de cana-de-açúcar. Revista Canavieiros, v.8, p.32-33, 2007.

Santos, F.; Borém, A.; Caldas, C. Cana-de-açúcar - Bioenergia, açúcar e etanol - Tecnologias e perspectivas . 2.ed. Viçosa: UFV. 2011. 637p.

Segato, S. V.; Pinto, A. de S.; Jendiroba, E.; Nóbrega, J. C. M. de. Atualização em produção de cana-de-açúcar. Piracicaba: cap 2, 2006. 415p.

Souza, Z. M. de; Prado, R de M.; Paixão, A. C. S.; Cesarin, L. G. Sistemas de colheita e manejo da palhada de canade-açúcar. Pesquisa Agropecuária Brasileira, v.40, p.271278, 2005.

Steiner, E.; Scott, J.; Mintom, P. N.; Winzer, K. An agr quorum sensing system that regulates granulose formation and sporulation in Clostridium acetobutylicum. Applied and Environmental Microbiology, v.78, p.1113-1122, 2011.

Vale, G. F. R. do; Carvalho, S. P. de; Paiva, L. C. avaliação do uso de polímeros hidroretentores no desenvolvimento do cafeeiro em pós-plantio. Coffee Science, v.1, p.7-13, 2006. 